Original Research Paper

\title{
The Use of the Super Absorbent Polymer as Water Blocker in Concrete Structures
}

\author{
${ }^{1}$ Moayyad Al-Nasra, ${ }^{2}$ Mohammad Daoudb and ${ }^{3}$ Taher M. Abu-Lebdeh \\ ${ }^{I}$ Department of Civil Engineering, Applied Science University, Amman, Jordan \\ ${ }^{2}$ Department of Civil Engineering, Zarqa University, Zarqa, Jordan \\ ${ }^{3}$ Department of Civil, Architectural and Environmental Engineering, \\ North Carolina A\&T State University, Greensboro, NC, USA
}

\author{
Article history \\ Received: 04-08-2015 \\ Revised: 17-09-2015 \\ Accepted: 17-09-2015 \\ Corresponding Author: \\ Taher M. Abu-Lebdeh \\ Department of Civil, Architectural \\ and Environmental Engineering, \\ North Carolina A\&T State \\ University, Greensboro, NC, USA \\ Email: taher@ncat.edu
}

\begin{abstract}
Adding super absorbent polymer to the concrete mix improves the performance of the concrete in its both stages; fresh concrete and hardened concrete. The super absorbent polymer has the ability to absorb relatively large amount of water and convert it into gel at the same time the volume increases proportionally. The new modified concrete has the ability to retain water in the form of gel which helps in the internal curing process of the concrete at its early stages and helps in blocking the water flow through voids and cracks in the mass of the concrete at its later stages. This study focuses on the ability of concrete to block the water flow through the concrete cracks. Several samples were prepared with different amount of super absorbent polymer added to the concrete mix expressed in percentage with respect to the weight of cement. Several cylindrical samples were prepared, but three different samples will be presented in this study. The samples were intentionally broken into two pieces. The two pieces are then put together forming artificially induced cracks in the samples. These samples were subjected to water pressure; falling head and constant head. The water flow through the induced crack in the sample is measured. The effect of the super absorbent polymer on the water flow is monitored and compared with the control samples, which is the sample prepared with no admixtures. The water tightness leading to complete water blockage is studied. The short term effect as well as the long term effect of the super absorbent polymer on the concrete water tightness is also studied. Several amounts of the super absorbent polymer expressed in terms of percentages of the cement weight are used in order to shed the light on the water tightness property of concrete. The increase of the amount of the super absorbent polymer in the concrete mix improves the internal curing properties of the concrete at the same generate more voids in the mass of the concrete which in turn reduces the strength of the concrete. Optimum amount of the superabsorbent polymer should be considered if the focus is the concrete strength. Also, the increase in the amount of the superabsorbent polymer in the concrete improves the water tightness of the concrete, which makes the concrete capable of blocking the water flow through the concrete cracks. There are several advantages of adding the super absorbent polymer to the concrete mix, including improving the concrete plasticity and workability at the same time improving the concrete mix stability and pump-ability.
\end{abstract}

Keywords: Concrete Curing, Concrete Strength, Water Blockage, Super Absorbent Polymer, Water Tightness 


\section{Introduction}

The main characteristic of the Super Absorbent Polymer (SAP) is its ability to absorb relatively large amount of water and converts it into gel, then releases it slowly with time. The volume of the gel increases in proportion with the amount of water absorbed. This property is very useful when it comes to watering plants over time. The expansion in volume has the tendency to clog the water pathways in the concrete mass and consequently improving its water tightness properties. This study focuses on the water tightness of the cracked concrete and the ability of the SAP to block the water flow though the concrete cracks. Several samples were prepared and studied. Only three will be presented in this study in order to simplify the presented concept. These samples are; plain concrete (mortar) with $0 \% \mathrm{SAP}$, concrete mixed with $0.15 \% \mathrm{SAP}$ and concrete mixed with $0.30 \% \mathrm{SAP}$. The content of SAP is measured as a percentage of the Portland cement used by weight.

The amount of water added to the fresh concrete is one of the most important key factors that affect the concrete properties, including water tightness, durability and strength. The water is an essential ingredient needed for the hydration process in the fresh concrete and for the curing process in the hardened concrete at its early stages. Excessive amount of water added in the fresh concrete improves the concrete workability in general, reduces the concrete strength and increases the drying shrinkage of the hardened concrete. Different admixtures were used to reduce the amount of water demand in the fresh concrete without jeopardizing the workability. Water reducer admixtures were used extensively in the ready mix plants.

The added super absorbent polymer to the concrete mix absorbs water and converts it into gels to be released later for the curing process. Excessive amount of SAP added to the concrete mix produces excessive voids in the mass of the concrete. These voids help in protecting the concrete from the hydraulic pressure generated by the freezing thawing process, osmotic pressure, or any generated pressure in the concrete mass. The concrete strength will be reduced due to the presence of these excessive voids. An optimum amount of the SAP to be added should be considered in order to balance between benefit of the internal curing and the loss of strength due to the excessive voids.

Jensen (2013) used superabsorbent polymers in concrete. His study focused on the strength and shrinkage of concrete. He concluded that the shrinkage of concrete due to loss of water to the surroundings is the cause of cracking both in the plastic and in the hardened stage. This type of cracking can effectively mitigated by slowing down the water loss. The superabsorbent polymers use in concrete has the potential to reduce concrete cracking. Jensen and Hensen (2001) studied the autogenous shrinkage phenomena in concrete. They concluded that the autogenous shrinkage may lead to cracking and affect concrete strength and durability, which is also, can be considered as technological challenge of high performance concrete. Addition of superabsorbent polymer in the ultra-high-performance concrete can be used to control the autogenous shrinkage. They also conducted tests that show that the shrinkage reduction due to superabsorbent polymer is related to a corresponding increase in the internal relative humidity of the cement paste. In addition, the use of superabsorbent polymer in concrete resulted in a reduction or elimination of stress build-up and related cracking during restrained hardening of these high-performance cementitious systems (Jensen and Hensen, 2002).

Al-Nasra (2013) studied the use of Sodium Polyacrylates as SAP in concrete. His study focused on determining the optimum amount of SAP to be added to the concrete in order to maximize the strength and durability of concrete. Al-Nasra concluded in his study that the optimum amount of SAP is 0.11 percent of cement by weight, which he showed to be the most effective amount to be used in concrete.

The gel produced by the superabsorbent polymers shrinks during the hydration process leaving voids in the concrete similar to the voids created by adding air entrainment agent to the concrete. The air bubbles left in the concrete are critical to absorb the hydraulic pressure due the water freezing. Water expands upon freezing about ten percent in volume generating hydraulic pressure in the concrete that has the potential to cause the concrete to crack. Providing voids in the concrete absorb the hydraulic pressure and provide addition space for the water to expand. The same can be said about the osmotic pressure in the concrete. The osmotic pressure is usually generated due to the difference in salt concentration in the water. This difference in salt concentration can be created by adding de-icer to the concrete top surface, for the purpose of melting the ice on the concrete. Also these voids can be useful to absorb other kinds of internal pressures in concrete including alkali reactivity pressure.

Snoeck et al. (2012) studied the use of superabsorbent polymers as a crack sealing and crack healing mechanism in cementitious materials. Their research focused on the use of the superabsorbent polymer to seal concrete cracks. As concrete cracks due to its low tensile strength and as harmful unfriendly chemicals may migrate into these cracks, the durability of concrete is endangered if no proper treatment or manual repair is applied. The first stage focused on hindering the fluid flow by swelling of superabsorbent 
polymers after they are exposed to a humid environment. The sealing capacity was measured by means of water permeability tests and through visualization of permeability tests by neutron radiography. They also concluded that the use of superabsorbent polymers is able to seal cracks and thus allow a recovery in watertightness as a decrease in permeability is noticed. The second stage focused on healing of small cracks by the use of fiber reinforced cementitious materials that have the ability to restore the mechanical properties. These mechanical properties were analyzed by four-pointbending tests and the crack closure was microscopically monitored. Cracks close through the combination of further hydration of unhydrated cement particles, precipitation of calcium carbonate and activation of the pozzolanic reaction of fly ash. Also they concluded that the desorption of superabsorbent polymers triggers healing in the vicinity of crack faces and cracks up to $130 \mu \mathrm{m}$ were able to close completely in wet/dry cycles due to the precipitation of calcium carbonate.

The process of curing involves maintaining satisfactory moisture content and temperature after concrete is placed in order to hydrate the cement particles and produce the desired hardened concrete properties. Proper curing can improve strength, durability, abrasion resistance, resistance to freeze-thaw cycles, de-icer scaling resistance and reduce concrete shrinkage. Traditionally, concrete has been cured externally either through the use of water curing or sealed curing. Curing either supplies additional moisture from the original mixing water or minimizes moisture loss from the concrete. Water may be bonded directly on the concrete surface or may use other methods like wet burlap bags or fogging near the surface of the concrete to prevent evaporation of water from the fresh concrete. Sealed curing is accomplished by applying some sort of sealant to the surface of concrete in order to prevent moisture loss. Internal curing can be divided into two categories. The first category is internal water curing in which an internal curing agent stores water during mixing which is gradually released as hydration processes. The second category is internal sealing which is very similar to external sealed curing in that its goal is to prevent the loss of moisture from the concrete (RILEM, 2007).

\section{Super Absorbent Polymer}

The super absorbent polymer used in this study is Sodium Polyacrylate, also known as water-lock, which is a sodium salt of polyacrylic acid with the chemical formula $\left[-\mathrm{CH}_{2}-\mathrm{CH}(\mathrm{COONa})-\right]_{\mathrm{n}}$ and broad application in consumer products. It has the ability to absorb as much as 200 to 300 times its mass in water. Sodium polyacrylate is anionic polyelectrolytes with negatively charged carboxylic groups in the main chain. Figure 1, shows the composition of the sodium polyacrylate.

Sodium polyacrylate is a chemical polymer that is widely used in a variety of consumer products for its ability to absorb several hundred times its mass in water. Sodium polyacrylate is made up of multiple chains of acrylate compounds that possess a positive anionic charge, which attracts water-based molecules to combine with it, making sodium polyacrylate a superabsorbent compound. Sodium polyacrylate is used extensively in the agricultural industry and is infused in the soil of many potted plants to help them retain moisture, behaving as a type of water reservoir. Florists commonly use sodium polyacrylate to help keep flowers fresh.

\section{Water Flow Test}

Three samples were prepared to study the water tightness of the concrete. Adding SAP to the concrete mix improves the concrete plasticity and workability at the same time improves the concrete stability. The gel produced by the SAP provides cushioning to the aggregates added to the mix. The color and texture of the concrete mixed with SAP will change too. The concrete mixed with SAP will have lighter color compared to the plain concrete. The shiny water surface of the fresh concrete seemed to disappear when using the SAP due to transforming the excess water in fresh concrete into gel.

The samples were prepared with the intention to focus on the water tightness property of the concrete and the ability of the concrete to block the water flow through the concrete cracks. The amount used in this study is above the optimum amount found by Al-Nasra (2013). Table 1 shows the mix design of the three samples used in this study. The samples are labeled as "P" for plain concrete sample with no SAP added to the mix, " $0.15 \%$ SAP" sample has $0.15 \%$ of SAP and " 0.30 SAP" sample has $0.3 \%$ of SAP by weight of Portland cement. The water cement ratio $(\mathrm{W} / \mathrm{C})$ is kept constant for all samples and taken to be 0.5 .

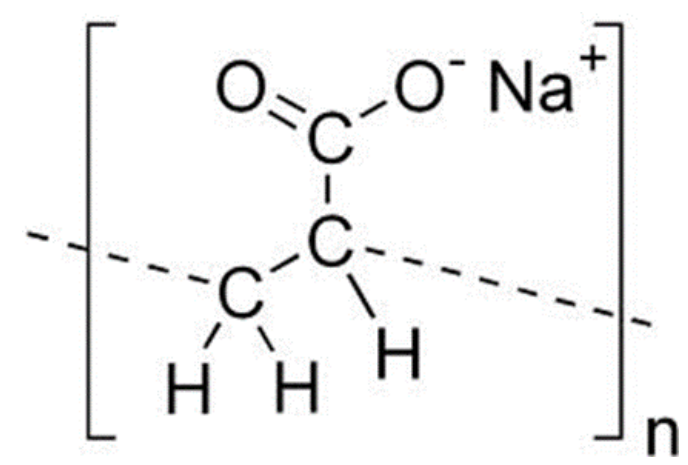

Fig. 1. Sodium Polyacrylate chemical compound 


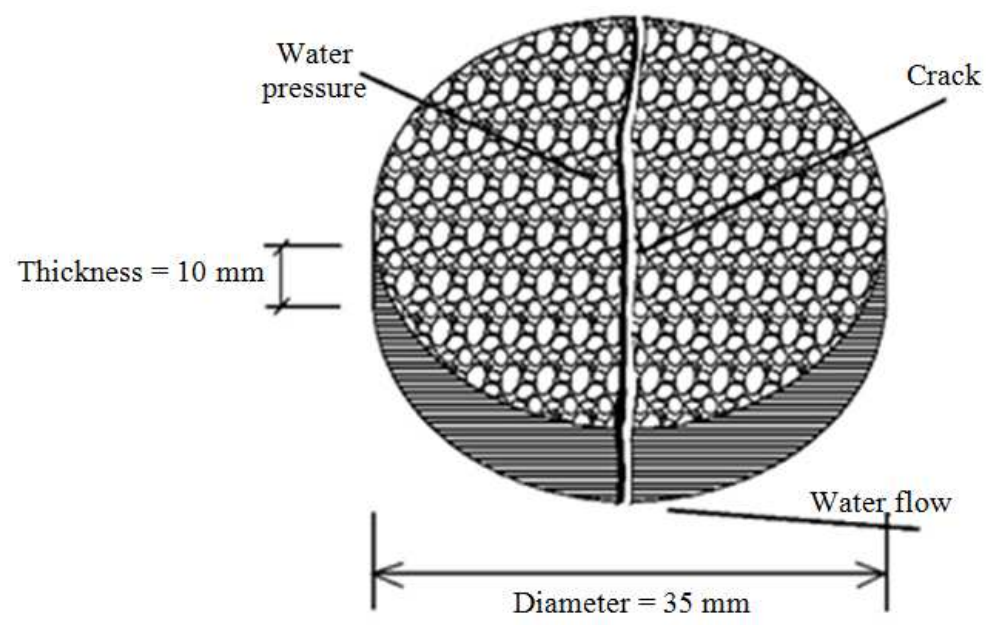

Fig. 2. Size and shape of samples used

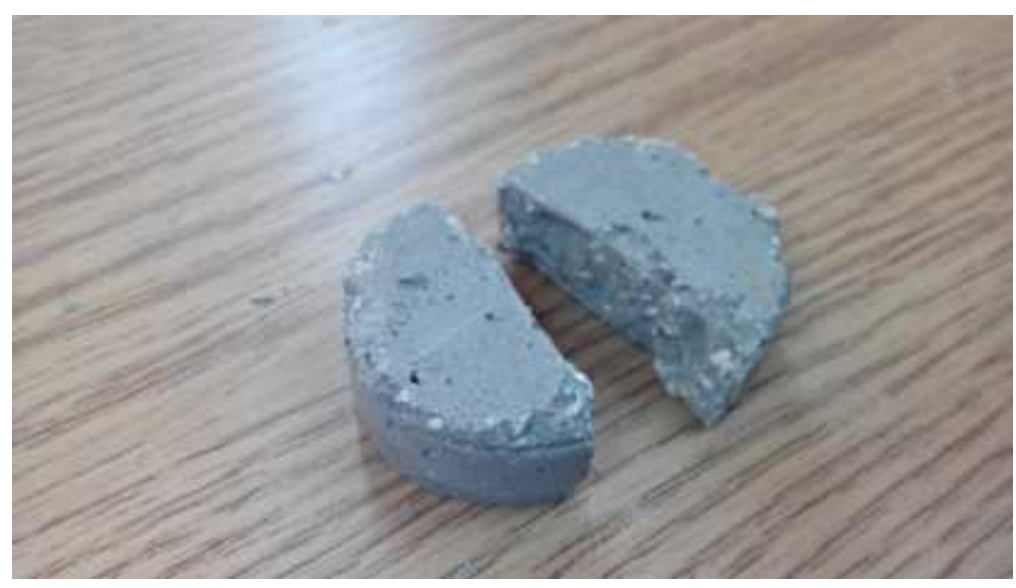

Fig. 3. Typical induced crack in a tested sample

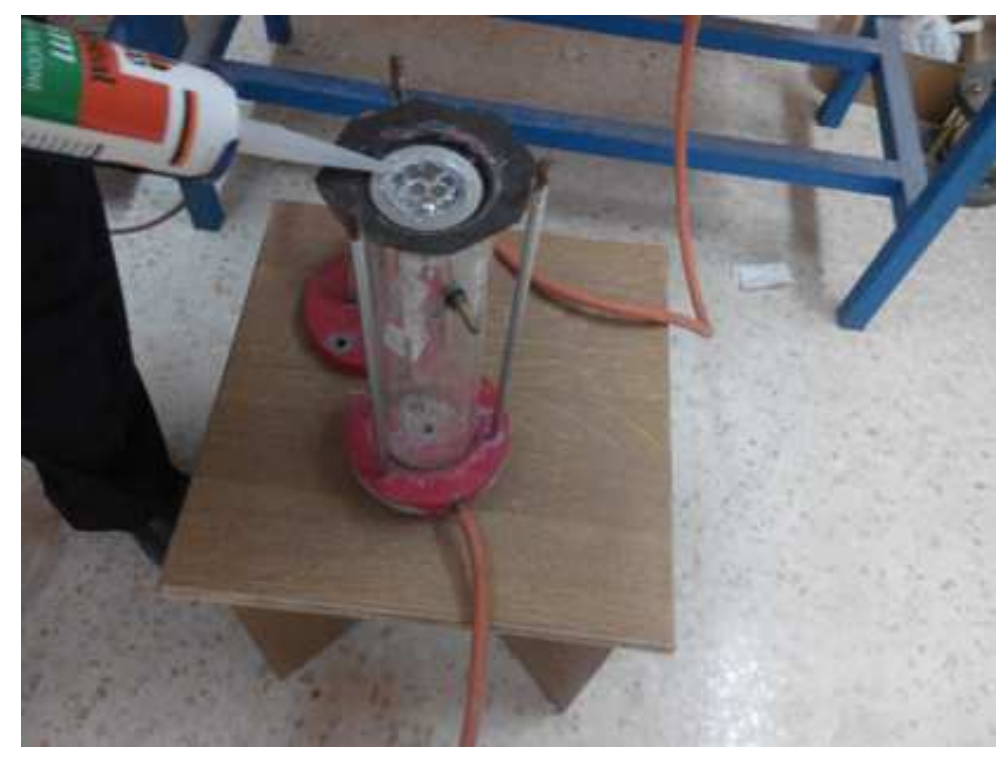

Fig. 4. Preparing the sample casing for the test 


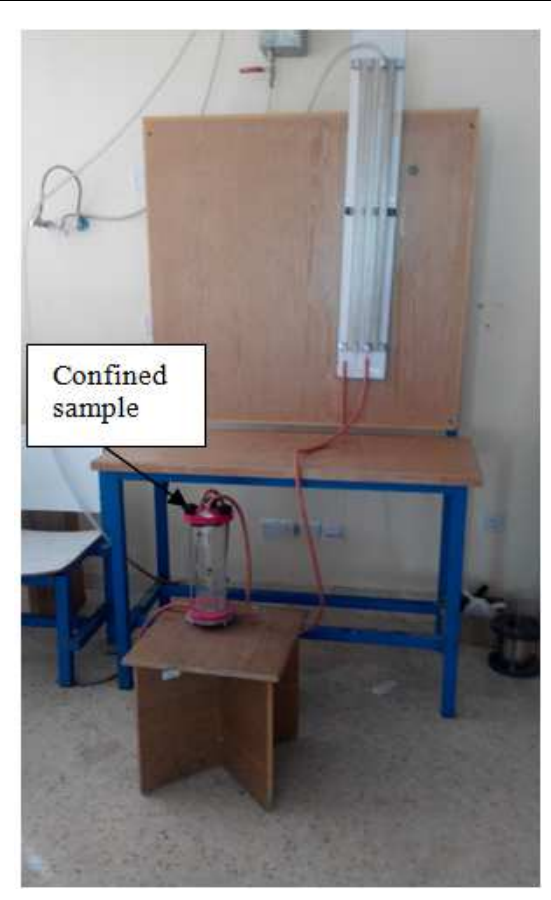

Fig. 5. Test set up

Table 1. Ingredients used

\begin{tabular}{llll}
\hline Sample ID & Sand $(\mathrm{gm})$ & Cement $(\mathrm{gm})$ & SAP $(\mathrm{gm})$ \\
\hline P-Plain & 200 & 100 & 0.00 \\
0.15-SAP & 200 & 100 & 0.15 \\
$0.30-$ SAP & 200 & 100 & 0.30 \\
\hline
\end{tabular}

Figure 2 shows the dimension of the samples used in this study. Special mold is used to make the test samples. The samples are of cylindrical shape of $35 \mathrm{~mm}$ base diameter and $10 \mathrm{~mm}$ height as shown in Fig. 2. These samples were subjected to bending stresses causing the sample to break in the middle as shown in Fig. 3. Figure 4 shows the casing of the sample. A sealant is applied at the perimeter of the concrete samples in order to prevent any leak at the perimeter and force the water to go through concrete crack under water pressure.

Two sets of water tightness tests were conducted; falling head and constant head. The first set of samples was subjected to falling head water pressure where the water pressure decreases by the increase in the water flow. The second set of samples was subjected to constant pressure. The water discharge though the sample can be calculated using the following formula:

$$
Q=V / t
$$

Where:

$Q=$ Water flow rate in $\mathrm{ml} / \mathrm{min}$

$V=$ Volume of water passing through the sample in milliliter $t=$ The measured time.

Figure 5 shows the experimental set up. The samples are confined in a chamber and tight sealed at the perimeter.

\section{Test Results}

The samples were tested under constant and variable water pressure. The water discharge is measured versus the time. The water flow is measured in $\mathrm{mL} / \mathrm{min}$. Each experiment is conducted over many days and weeks. Short term readings were taken at the beginning of the experiment in terms of minutes then readings were taken over several hours intervals. The test is even extended beyond the stoppage time. The stoppage time is the time at which the water flow remains zero for several hours and days. The plain concrete samples have no stoppage time, since the water kept flowing constantly especially under constant pressure. The samples prepared with SAP exhibit stoppage time depending on the amount of SAP used in the concrete mix. Only two types of samples mixed with SAP were considered in this study, but the trend is very obvious. The increase in the amount of SAP in the concrete mix, the sooner the stoppage time will be.

Table 2 shows a partial list of the reading taken for the falling head test. The water flow in the sample made of plain concrete $(0 \%$ SAP) decreases due to the drop in the $0.15 \%$ SAP showed low rate of water flow and this water flow decrease due to both the drop in the water pressure and the effect of the SAP in the concrete. The water stopped flowing in the sample prepared with $0.15 \%$ SAP after $192 \mathrm{~h}$ ( 8 days later) at water pressure $62 \mathrm{~cm}$ of water column. The water flow trickled down very rapidly until few drops every several hours before the water stopped flowing completely after $8 \mathrm{~h}$. The sample prepared with $0.30 \%$ SAP exhibited even a better water blockage than the one made with $0.15 \%$ SAP. The water flow in the sample prepared with $0.30 \%$ SAP was at a higher rate at the beginning due to several factors mainly related to the induced crack in the concrete sample. It is not doable to create completely identical cracks in the concrete samples. But soon the sample was able to stop the water flow in $1.2 \mathrm{~h}$ at water pressure $101 \mathrm{~cm}$ of water column. Figure 6 shows the rate of changing the applied water pressure with time. The samples made with SAP show the ability to retain water under relatively high pressure compared with the plain concrete sample. The sample made with $0.3 \%$ SAP kept a sustained water pressure after the blockage time. Figure 7 shows the water flow in $(\mathrm{ml})$ with time. The rate of flow in the sample made of plain concrete 
was relatively high compared with the samples prepared with SAP. Figure 8 shows the comparison between the two samples made with different amount of SAP. The effect of the amount of SAP mixed with concrete is illustrated in the figure under falling head pressure. The higher the percentage of SAP used in the concrete mix the better water blocker the concrete will be.

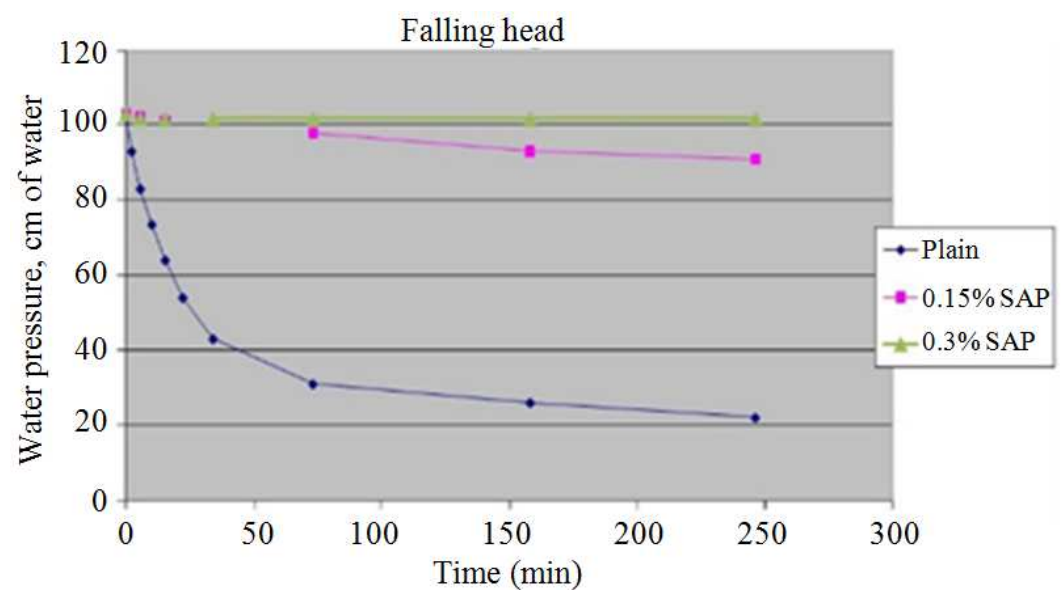

Fig. 6. Pressure drop measurement with time

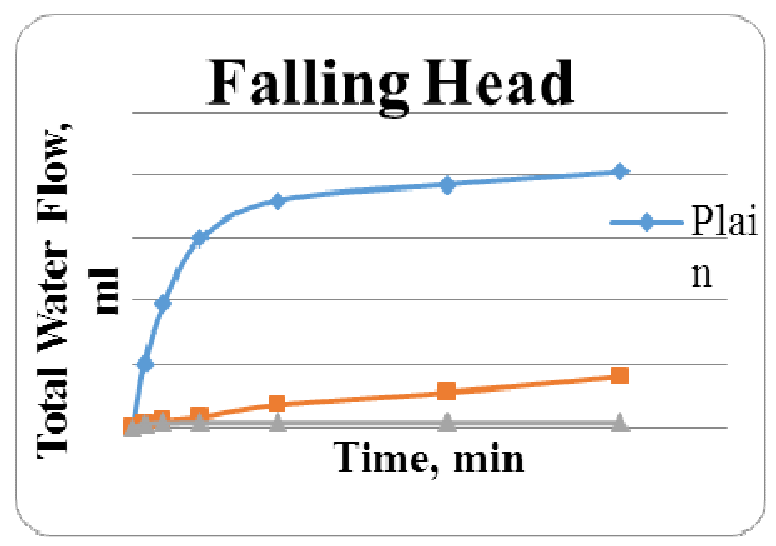

Fig. 7. Falling head water flow with time

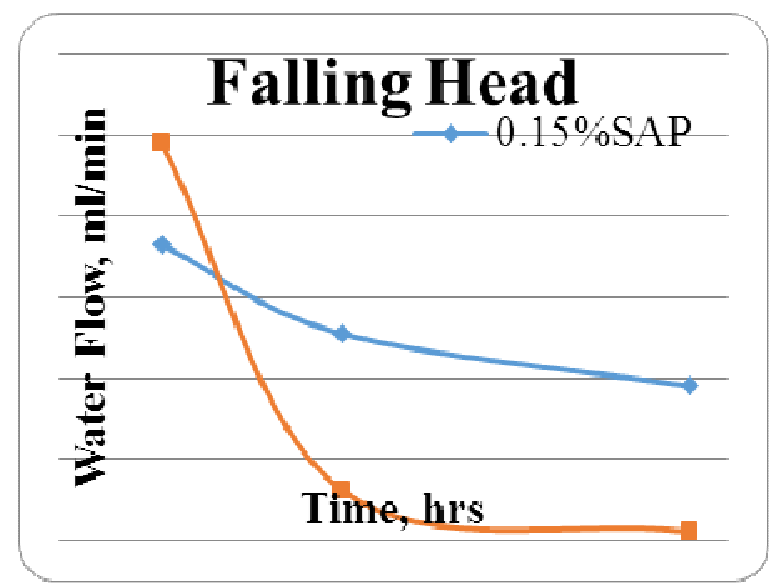

Fig. 8. Effect of SAP on the water flow under falling head pressure

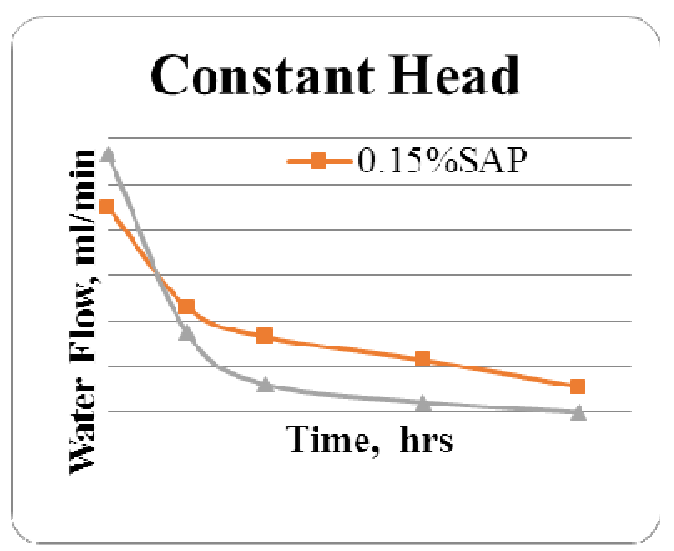

Fig. 9. The effect of SAP on the water flow rate under constant head pressure

Table 2. Falling head summarized results

\begin{tabular}{llll}
\hline & Falling head, Water Flow, $\mathrm{ml} / \mathrm{min}$ & \\
Time, $\mathrm{h}$ & Plain concrete & $0.15 \% \mathrm{SAP}$ & $0.30 \% \mathrm{SAP}$ \\
\hline 0.10 & 14.7 & 0.73 & 0.98 \\
0.25 & 9.0 & 0.51 & 0.12 \\
1.0 & 4.6 & 0.38 & 0.02 \\
1.2 & 1.5 & 0.36 & 0.00 \\
\hline
\end{tabular}

Table 3. Constant head summarized results

\begin{tabular}{llll}
\hline & \multicolumn{3}{l}{ Constant head, Water Flow, $\mathrm{ml} / \mathrm{min}$} \\
Time, hrs & Plain concrete & $0.15 \% \mathrm{SAP}$ & $0.30 \%$ SAP \\
\hline 0.00 & 27.3 & 0.90 & 1.13 \\
12 & 26.9 & 0.46 & 0.36 \\
48 & 26.8 & 0.23 & 0.04 \\
72 & 28.5 & 0.11 & 0.00 \\
\hline
\end{tabular}


The samples were then tested under constant pressure in order to focus on the effect of the SAP in the concrete as a water blocker. The water pressure is kept constant at $103 \mathrm{~cm}$ of water column. Table 3 shows a partial list of the results. The water flow in the sample prepared with plain concrete $(0 \%$ SAP) exhibited almost a constant water flow around 27 $\mathrm{ml} / \mathrm{min}$. The sample prepared with $0.15 \%$ SAP showed rapid drop in the water flow rate. The flow rate in that sample eventually trickled down to few drops per hour in about 20 days. The samples prepared with $0.30 \%$ SAP showed a much better results as far as the water blockage is concern. The water flow stopped completely in about $72 \mathrm{~h}$ ( 3 days). Figure 9 shows the effect of the amount of SAP used in the concrete mix on the water flow rate under constant pressure.

\section{Conclusion}

Adding a very small amount of super absorbent polymer in the concrete mix makes a big difference in the concrete behavior in its two stages as fresh concrete and as hardened concrete. The use of super absorbent polymer in the concrete has promising potential to improve several concrete properties including the water tightness. The concrete mixed with SAP makes the concrete more plastic and improves its workability and stability. Also it has the potential to make the concrete as self sealing concrete. The test results showed that the increase in the amount of SAP used in the concrete mix improves substantially the water blockage property of the concrete. All of the tested samples were broken into two separate pieces to induce artificial cracks. The SAP was able to block the water flow through the concrete cracks at a relatively low percentage of $0.3 \%$ of the cement used in the mix in $72 \mathrm{~h}$. The concrete sealing property improves with time due to the continuous expansion of the formed gel. The time of water blockage can be reduced substantially by adding more SAP. Adding more SAP to the concrete mix creates more voids in the concrete mass which in turn reduces the concrete strength. Optimum and balanced amount of SAP should be considered in the concrete mix design.

\section{Acknowledgement}

This paper summarizes the findings of a research work supported in part by the Applied Science University, Amman-Jordan and by Zarqa University, Zarqa -Jordan. Any findings, conclusions and recommendations expressed in this study are those of the authors.

\section{Author's Contributions}

Moayyad Al-Nasra: Participated in all experimental plan and testing, data-analysis and contributed to the writing of the manuscript.

Mohammad Daoudb: Participated in experimental plan and testing, data-analysis and contributed to the writing of the manuscript.

Taher Abu-Lebdeh: Participated in experimental plan, data-analysis and contributed to the writing of the manuscript.

\section{Ethics}

The authors would like to disclose that Dr. Taher M. Abu-Lebdeh (Co-author) is a member of the editorial board for the American Journal of Engineering and Applied Sciences.

\section{References}

Al-Nasra, M., 2013. Optimizing the Use of Sodium Polyacrylate in Plain Concrete. Int. J. Eng. Res. Applic. 3: 1058-1062.

Jensen, O.J. and P.F. Hensen, 2001. Autogenous deformation and RH-change in perspective. Cement Concrete Res., 31: 1859-1865. DOI: 10.1016/S0008-8846(01)00501-4

Jensen, O.J. and P.F. Hensen, 2002. Water-entrained cement-based materials: II. Experimental observations. Cement Concrete Res., 32: 973-978. DOI: $10.1016 / \mathrm{S} 0008-8846(02) 00737-8$

Jensen, O.M., 2013. Use of superabsorbent polymers in concrete. Concrete Int., 35: 48-52.

RILEM, 2007. Internal curing of concrete-state-ofthe-art report of RILEM technical committee 196ICC. State of the Art Report, RILEM Publications SARL.

Snoeck, D., K. Van Tittelboom, N. De Belie, S. Steuperaert and P. Peter Dubruel, 2012. The use of Superabsorbent polymers as a crack sealing and crack healing mechanism in cementitious materials. Proceedings of the International Conference on Concrete Repair, Rehabilitation and Retrofitting, (RRR' 12), Cape Town, South Africa, pp: 152-157. 